\title{
El rol de las prácticas artísticas inmersas en los procesos de formación motriz en la Facultad de Cultura Física Deporte y Recreación*
}

\author{
Jacquelin Albarracin Giraldo* \\ Recibido: febrero 12 de 2014 • Evaluado: marzo 15 de 2014
}

Aceptado: abril 19 de 2014

\section{Resumen}

El presente artículo habla sobre el aporte de artes como el teatro físico, la danza y la música en los procesos de formación motriz con los estudiantes de la Facultad de Cultura Física, Deporte y Recreación. Se partió de experiencias y aprendizajes vividos en el aula de clase y del trabajo sensocorpo-creativo relacionado directamente con los contenidos o las temáticas sustentadas en el Proyecto Educativo del Programa (PEP).

Presenta reflexiones orientadas hacia los procesos en la enseñanza de las artes que van más allá de un fin en sí mismo, en busca de articular lo propuesto en la acción motriz, en reciprocidad con los contenidos de las técnicas corporales y somáticas que implican movimiento y conciencia.

Palabras clave: Cuerpo, artes, psicosomático, interdisciplinario, creación, percepción, enseñanza, proceso.

"El presente artículo nace de la reflexión del aporte de las prácticas artísticas en los procesos formativos de los estudiantes de la Facultad de Cultura Física, Deporte y Recreación.

" Licenciada en Artes Escénicas y Técnicas Corporales, dramaturgista, actriz y directora de teatro. Maestrante en Procesos de Formación de la Enseñanza de las Artes en la Universidad de las Artes (La Habana, Cuba). Docente de Expresión Corporal y Artística en la Universidad Santo Tomás, Facultad de Cultura Física, Deporte y Recreación. Correo: jacquelinealbarracin@usantotomas.edu.co. 


\section{The role of artistic practices in the processes of locomotor training from phisical culture, sport and recreation program}

\section{Abstract}

This article involves subjects such as the contribution of arts in physical theatre, dance, music into the motor training, matters on which Physical Culture, Sport and Recreation's students worked on. Having as a starting point the experiences and the learning process developed in the classroom, on which is based the work of sensitive-body-creation directly related with the contents and/or thematic sustained in the Program's Educative Proyect (PEP).

Furthermore, it shows some reflections that are focused on the teaching process in art field that goes further than having a single objective itself, trying to articulate the proposals in the motor action in reciprocity with the contents of the body techniques and somatics worked in art lessons, specifically those that include movement and conscience.

Keywords: Body, arts, psychosomatic, interdisciplinary, creation, perception, teaching, process. 


\section{Introducción}

Ahí, en la universidad, la razón da cuenta de sí misma, pero, ¿qué pasa con el arte?, ¿cómo se mide su valor académico?, ¿es la razón del arte capaz de dar cuenta de su propia sinrazón?

Doris Lessing

Reflexionar y sustentar la pertinencia de las prácticas artísticas en un ámbito deportivo puede convertirse en un proyecto de investigación propio de la experiencia del movimiento, si se considera que este se gesta desde el momento exacto en que el cuerpo está conectado con la respiración, la digestión, la circulación de la sangre en el cerebro, el flujo de las ideas, la razón, la emoción, los sentidos y las motivaciones. Se puede decir que desde allí se empieza a revelar la vorágine, que solo cobra sentido cuando, por medio de la danza, el teatro físico (fundamento de las actividades artístico-culturales) y la música, se pueden crear espacios de reflexión y de resemantización, lo que le da otro enfoque cognoscitivo al estudio del cuerpo en relación con la vida, la didáctica y la pedagogía.

En esta búsqueda, orientada a argumentar el aporte de las prácticas artísticas en los procesos de formación en la Facultad de Cultura Física, Deporte y Recreación, en una extensión pragmática sobre la idea que cada profesional tenga del concepto de corporalidad, se hace necesario citar los siguientes ejes temáticos expuestos en el Proyecto Educativo del Programa - PEP (2012) ${ }^{1}$, con el fin de ir dando plataforma interdisciplinaria al presente texto.

\section{Formación interdisciplinaria}

Los estudiantes del programa de Cultura Física, Deporte y Recreación se caracterizan por una formación integral que incluye la revisión de ciencias

1 Se toman específicamente los ciclos pedagógicos y los núcleos problémicos, formación interdisciplinaria y fundamentación teórica del programa. 
afines al movimiento y de aquellas que aportan a la adquisición de competencias necesarias para la interpretación, el análisis y la aplicación de la acción motriz dentro del contexto económico, político y sociocultural colombiano. (Proyecto Educativo del Programa [PEP], 2012, p. 62)

En la perspectiva del movimiento, estudiado en la acción motriz con enfoques artísticos como la danza, la construcción de puestas en escena está dirigida hacia la teatralidad, pero más exactamente hacia los procesos de formación-experimentación-creación para el fortalecimiento en el desarrollo de las actividades motrices que se llevan a cabo con los estudiantes. La formación integral a la que se refiere el presente artículo deja al descubierto que no solo constituye un fin per sé, con la "Muestra es Nuestra", sino que también logra aportar a distintos campos de la educación del movimiento.

El hallazgo de problemas y soluciones a nivel motriz y de conciencia corporal, tan evidente en los estudiantes de los primeros semestres (formación básica), ayuda a revelar dificultades que van más allá del plano físico y que se van desenmascarando mediante ejercicios y técnicas. Los profesionales del movimiento (entiéndase danza o teatro), en el estudio y la práctica de técnicas corporales sobre las que sustentan sus respectivos entrenamientos y que contribuyen al pleno desarrollo de la acción motriz sin dejar de lado el progreso cognoscitivo que implica moverse complejamente, proponen:

Reformular el movimiento como un vehículo de formación de los sujetos en cuanto es la materia prima de la actuación y de la construcción/desarrollo del sistema perceptivo humano. La posibilidad de establecer contacto con el entorno y promover la comprensión de la información sobre el mundo, ¿quién conoce?, ¿qué conoce?, de las maneras particulares de conocer de los sujetos ¿cómo conoce? Finalmente, la necesaria acción de pensar en los sujetos que participan y de sus acciones como agentes del evento cognoscitivo. ¿Cómo se pasa de un estado de conocimiento a otro? (Mallarino, 2010, p. 13)

\section{Técnicas somáticas trabajadas en las clases y sus beneficios}

En cuanto al trabajo de autoimagen que se desarrolla en las clases con los estudiantes y al estudio de los planos de la psico-somatización, se sustentan las siguientes técnicas: 
Rolfing. Técnica desarrollada por la doctora Ida Rolf a mediados de los años treinta, orientada a reestructurar el cuerpo a partir de su alineación y su balance, lo que implica liberar las tensiones acumuladas durante la vida. Es por ello que una mala alineación del cuerpo en relación con la fuerza de gravedad puede llevar a sufrir tensiones crónicas, lo que disminuye la vitalidad, y el funcionamiento biológico y psicológico.

Feldenkrais. El método Feldenkrais consiste en el movimiento consciente y en la atención dirigida utilizando patrones de movimiento eficientes y sanos; ayuda a mejorar la postura y a perfeccionar habilidades motrices. Es importante anotar que en este método el trabajo con la imaginación es vital, porque el paciente debe imaginar la estructura que está moviendo, creando un acercamiento mental sobre los tendones, los músculos y los huesos en su composición y dinámica. Se establece una conciencia diferente creando un biorritmo distinto en cada una de las secuencias a trabajar, según lo que se quiera aliviar o fortalecer. No se trabaja a partir del esfuerzo muscular o de la flexibilidad: "Lo que busco es una mente más flexible". El método Feldenkrais tiende a ser más una forma de autoeducación y de autoconocimiento.

Alexander. La técnica Alexander está diseñada con el objetivo de hacer un correcto uso de la estructura corporal y energética, lo que permite el paso a otro tipo de conciencia y esfuerzo dirigido a actividades que sí los requieren como practicar algún deporte, danzar, tocar piano, interpretar una escena, cantar o vivir, con facilidad en el movimiento.

Klein Técnique. La técnica Klein permite una comprensión distinta del movimiento corporal, debido a que todas las direcciones posibles realizadas con el cuerpo parten desde la conciencia ósea; es decir, el músculo obedece al impulso del hueso permitiendo que la experiencia ocurra a nivel físico; el cuerpo entiende a nivel de conexiones no de sensaciones, porque es posible que ellas varíen de un día a otro, de modo que la conexión es una acción más concreta y en el momento de experimentarla es posible que la huella psíquica no se borre con facilidad.

Para lograr esto, es necesario establecer una conexión mental y física con el hueso, dejando de usar ciertos músculos superficiales y encontrando 
la musculatura cercana que soporta toda la estructura, lo que permite ampliar el rango de movimiento y su eficiencia. Es una técnica somática desconocida, lamentablemente, en Colombia y en algunas partes de América Latina; sin embargo, las personas que han tenido la oportunidad de formarse en ella han sentido sus beneficios al poder establecer otro tipo de conexiones con la sabiduría del cuerpo.

Gyrokinesis. Esta técnica fue creada a mediados de los años ochenta por el bailarín, gimnasta y deportista húngaro Juliu Horvath, quien al sufrir una lesión en el tendón de Aquiles, se ve obligado a abandonar su carrera. En ese momento, crea este sistema y empieza a impartirlo, a practicarlo y a remodelarlo en Nueva York, donde se instala y abre el primer centro de Gyrotonic Expansion System.

Esta técnica trabaja las articulaciones y los músculos, a través de movimientos rítmicos y ondulantes que abrazan los principios fundamentales de la natación, la danza, el yoga, el taichí y la gimnasia. Es una aproximación integral de acondicionamiento físico que enfatiza la estabilidad del centro, la alineación correcta del cuerpo y su equilibrio.

Son técnicas somáticas para entrenamiento de deportistas, de artistas que se dedican al physical theater o a la danza, $\mathrm{y}$ de profesionales del cuerpo en movimiento, que se apoyan en este tipo de dinámicas para desarrollar procesos de aprendizaje en disciplinas que no necesariamente tienen que ver con el arte y que ayudan a desenvolver humanidades que se encuentran inmersas dentro de pieles, por lo general rústicas debido a insondables memorias. Estas humanidades algunas veces no dependen de la voluntad, sino que se desprenden, en su mayoría, de herencias familiares o experiencias vividas en el recorrer de este mundo de sensaciones (algunas) exquisitas, otras no tanto, algunas dolorosas y que se quedan en la memoria psico-corporal.

"La praxiología reconoce que cada persona tiene una manera singular de manifestar su motricidad, cuya expresión es reflejo de su dotación genética, de su experiencia, de su historia personal y de su cultura" (PEP, 2012, p. 24). Se considera que la dificultad no radica en este planteamiento, sino en la manera de encontrar métodos que ayuden a redescubrir o a confrontarse, posibilitando espacios para que cada estudiante, con la humanidad que lo compone, explore para tener claridad hacia dónde se dirigen sus esfuerzos. 
En este contexto posmoderno crece, según Crum (2000, citado por PEP, 2012, p. 20), la cultura del cuerpo: el escepticismo, el relativismo, el cambio, la superficialidad y la fugacidad llevan a los seres humanos a pensar en su corporeidad, en su presencia física en el mundo, como un punto relativamente estable de su autorrealización.

Ello conlleva un redescubrimiento del cuerpo, en un momento en el que las demandas físicas y de movimiento disminuyen y son reemplazadas por la tecnologización de la vida, lo que lleva a los sujetos a desconectarse de su cuerpo y a desvirtuar su sentido y su capacidad; a "un tipo de vida repleta de ilusiones y pensamientos vanos que alejan a las personas de su realidad sintiente, de su ser corpóreo" (Zubiri, 1984 citado por Lagardera, 2009, p. 12).

Partiendo de este planteamiento, es importante resaltar la correspondencia entre algunos de los contenidos que se trabajan en los espacios académicos que conciernen a las prácticas artísticas y lo que traza el PEP de la facultad:

Eje funcional: Educación del movimiento. Se ha orientado a la motricidad general y específica, con el propósito de favorecer el desarrollo de las capacidades orgánicas y motrices y permitir el acceso de los individuos al ámbito cultural que constituye la práctica de las actividades físico-deportivas y de expresión. (PEP, 2012, p. 28)

\section{Hablando de utopías...}

Retribuyendo el valor que da la acción motriz a los contenidos de los espacios académicos relacionados con los contenidos de las prácticas artísticas (Fundamentos de las Actividades Artístico-culturales, Música, Expresión Corporal y Artística) y teniendo en cuenta el válido cuestionamiento que hacen los estudiantes del programa respecto a la importancia o efectividad del arte en su carrera, los docentes que acompañan este proceso tienen la labor de extender la invitación a enriquecer espacios de exploración creativa, física, corporal y mental. Esto con el fin de que ayuden a profundizar en la investigación sobre las cuantiosas maneras de reencontrar sus cuerpos en la creación, en la limitante, en la dificultad, en el encuentro con esa voz interior que algunos obvian, en la necesidad de buscar cuestionamientos que 
lleven a ser mejor persona, a descubrir de lo que son capaces de hacer con los movimientos que les pertenecen, explorando la poética de la dificultad, del error, en el desaparecer por unas horas de sí mismo para encontrarse y convertirse en otro que paradójicamente no es otro que el yo.

Esto se hace posible mediante la experiencia de organizar un sencillo ejercicio escénico de 7 minutos, lo cual representa horas y horas de trabajo, de confrontación, de ensayo, sustentado en la indagación del cuerpo y del movimiento narrativo. Suena muchas veces a utopía. Cuando al mencionar la palabra ARTE, muchos estudiantes dicen: “iPero si es que yo no vine aquí a ser artista, profesora!”. Sin embargo, se ve su actitud comprometida en la preparación de las intervenciones para la muestra, se percibe su ansiedad el día de la presentación final o se encuentra uno con gratitud un abrazo al final del semestre, y uno los escucha decir “ ¡lo logramos!”, y al preguntarles: “¿Qué lograste?”, algunos responden: "Vencer el miedo”, "Creer en la capacidad de hacer lo que no creía que podía”, "En mi liderazgo, en mi fuerza que no se halla precisamente en mis músculos".

¿Utopías?... ¿para qué sirven? Es una pregunta que suscita el poema de Eduardo Galeano y que algunas veces es leído en las clases:

Ella está en el horizonte. Me acerco dos pasos, Ella se aleja dos pasos más. Camino diez pasos y el horizonte se corre Diez pasos más allá. Por mucho que yo camine nunca la voy a alcanzar. ¿Para qué sirve la utopía? Sirve para eso: para caminar.

\section{Sobre la responsabilidad social de lo aprehendido en la academia}

En esta lógica de encontrarse con fragmentos del PEP, apartes que se comparten con la labor de ser una pedagoga del arte, se crean uniones que enriquecen la teoría llevada a la práctica; en esa unión dialéctica de conceptos, de aciertos que logran constituirse en el arte del movimiento, sea danza o teatro físico. En su quehacer, se enriquece también con planteamientos como la praxiología, disciplinas que extienden la capacidad de entender diversas dinámicas desde otros ángulos, y eso verdaderamente crea vías de comprehensión tan significativas que las personas que más se benefician son 
los propios estudiantes, porque tendrán una visión más holística de lo que el movimiento corporal significa; y si se quisiera ir más lejos, en la labor tan grande que les espera cuando sean profesionales y las implicaciones éticas que este hecho abarca.

La educación de los ciudadanos de un país es una de las necesidades más importantes a satisfacer en cualquier sociedad, y es un problema social esencial. Una nación moderna requiere que todos sus miembros tengan un cierto nivel cultural que les posibilite desarrollar una labor eficiente. Un país desarrollado, o que aspire a serlo, tiene que plantearse el objetivo de que todos sus miembros estén preparados para ejecutar un determinado papel, entre las múltiples funciones que se llevan a cabo en el seno de dicha sociedad. Aquel país en el que todos sus ciudadanos ejecutan sus labores a un nivel de excelencia es una nación preparada y puede ocupar un lugar de vanguardia en el concierto universal de los Estados. Una sociedad está preparada cuando todos o la mayoría de sus ciudadanos lo están; un individuo está preparado cuando puede enfrentarse a los problemas que se le presentan en su puesto de trabajo y los resuelve.

En esta medida, es importante resaltar la concordancia en lo expuesto por el PEP, relacionándolo con lo antes expuesto:

Pensar el cuerpo con perspectiva compleja permite reconocer que cualquier evento que se lleve a cabo en alguna de sus dimensiones tendrá impacto sobre las otras, lo que se verá igualmente reflejado en las relaciones que se establezcan con los otros y con la naturaleza. En consecuencia, escuchar el cuerpo desde cada una de las acciones que desarrolla y vivirlo conscientemente favorece la percepción y la expresión del sí mismo tanto como la relación con otros, en cuanto moviliza el cuestionamiento sobre la propia existencia y sobre cómo esa forma de existencia repercute en sí mismo, en la relación con los otros y con el entorno. Consecuentemente, visualizar a un ser corpóreo desde una comprensión sistémica permite enfocar el trabajo pedagógico o terapéutico, no solo en este ser sino en su relación con el mundo. (PEP, 2012, p. 31)

En el necesario viaje a pie que debería ser nuestro aprendizaje por el mundo, dice Ospina (2011):

Nadie se aplica de manera abnegada y obstinada sino a aquello que lo estremece profundamente. Y esto puede decirse de todas las disciplinas, 
porque, en realidad, no importa cuál sea la disciplina escogida, si corresponde a una vocación, la persona terminará haciendo de ella un verdadero arte.

Se considera que el impulso, la inteligencia, la perspicacia y la fuerza creadora, la complicidad, la camaradería, el don de alteridad que proporciona un proceso de intervención artística puede contribuir a la academia, siempre y cuando sea un propósito el permitir de manera asertiva la verdadera esencia de lo interdisciplinario, de saber qué tan abierto se está al influjo de nuevas dinámicas al estar redescubriendo, construyendo, deconstruyendo, reconstruyendo constantemente lo que significa ser humano. Todo esto en la noble tarea de concienciar a los estudiantes de que cualquier aporte significativo que haga cualquier disciplina para su carrera y también para su vida es sumamente valioso, porque la vida no debe divorciarse de la profesión a la que cualquier persona se dedique, porque la vocación debe darle un valor agregado a la dignificación de cada una de las personas, en su día a día.

\section{El viaje que se emprende fuera de nuestro elemento}

Las reflexiones que se pueden emprender cuando no necesariamente un maestro en artes se desempeña en el campo directo de su disciplina crean dinámicas que posibilitan a estos profesionales esclarecer, por no decir aterrizar, ciertos criterios sobre su profesión.

Es claro que este planteamiento se dirige a los maestros en artes que ven en el campo de la pedagogía y de la didáctica una manera de formar artistas, en un punto en el que cada estudiante encuentre que las lecciones del arte van más allá de su propio dominio en el sentido básico de las técnicas; en un sentido pragmático y profundo de lo que significa ser artista en una sociedad como la actual.

Sin embargo, buscar, cuestionarse, replantear, confrontarse, son verbos que claramente llevan a emprender acciones que generen campos en donde se piense y se construya sobre qué criterios o herramientas se sustenta la enseñanza de alguna de las prácticas artísticas para profesionales que no tienen relación con disciplinas como el teatro, la danza, el arte plástico, el arte audiovisual y la música. 
Se considera que la dificultad y la virtud de muchos artistas y profesionales del arte es hallarse fuera de su elemento, es decir, fuera de contextos laborales y creativos que por lo general cuestionan, muchas veces con crueldad e ignominia, su postura frente a la vida, frente a una nación, frente a una responsabilidad tan grande y tan fundamental como ser formador y artista al mismo tiempo. La vida no tiene límite de tiempo en las horas invertidas, cuando se profundiza sobre temas, imágenes, palabras, gestos, poéticamente en la electricidad de los desprendimientos en cualquiera de las esferas de la vida; esa vida que tanto inspira, que tanto cuestiona procesos relacionados con lo netamente humano, con el desenvolvimiento en la sociedad, con ese denso careo entre el predicar-hacer. En ese proceso en el cual lo turbio, de un momento a otro, se hace transparente, en el hallazgo, en la reconciliación del olvido y la memoria, en el deber ser y el deber hacer.

Por ahora, queda seguir avanzando en las preguntas, seguir creando estrategias para hallar respuestas, seguir empeñándonos en creer en procesos que ayuden a formar personas dueñas de sus vivencias y experiencias, autónomas, comprometidas, , que respeten tanto su integridad como la de los otros, que no transgredan el principio fundamental de nunca pasar por encima de sí mismos. Lo que cada quien haga por su propio aprendizaje tiene un valor incalculable; que la naturaleza de sus acciones y palabras los lleve a ser ciudadanos libres, éticos, pensantes, transformadores de su propia realidad, que trabajen cada día por superar sus propios miedos, por conocerse cada vez más, por ser críticos de sus posturas y hábitos. Que tomen conciencia de que el día de mañana serán otros los que saldrán beneficiados de su ética, de su aprendizaje y sus experiencias, y que la responsabilidad es grande cuando se es despojado del cómodo y protegido elemento, y que solo afuera de esa plácida y mimada esfera se puede descubrir de qué material realmente están hechos.

Este artículo, por ahora, concluye con una cita del escritor colombiano William Ospina, considerando lo respetable de sus letras y sentidos. Logra sustentar la importancia y validez del arte en la academia y en la formación:

Todo profesional comprometido y apasionado es un artista; y arte no significa aquí solo la búsqueda de armonía y de ritmo, de belleza y refinamiento, sino de sentido profundo, de fuerza creadora, de revelación y de fecundidad. 
Se admite la necesaria confrontación como formadores; en la búsqueda de cuestionamientos que requieren de una vital templanza como solo puede demandar de nosotros la vida misma, nos damos cuenta de que algún día tendremos que volver a escribir con todo el cuerpo en esa constante labor de reconciliarnos con el mundo.

\section{Bibliografía}

Bernard, M. (1994). El cuerpo: un fenómeno ambivalente. Barcelona: Ediciones Paidós.

Castro, J., \& Uribe, M. (1998). La educación somática: un medio para desarrollar el potencial humano. Revista Educación Física y Deporte, 20(1), 31-43. Recuperado de http://www.metodofeldenkrais.com/wp-content/ uploads/2014/09/EDUCACION-SOMATICA.-pdf.pdf

Freire, P. (2006). Pedagogía de la autonomía. São Paulo: Siglo XXI Editores.

Gardner, H. (1973). Las artes y el desarrollo humano. Nueva York: Wiley.

Gerda, A. (1998). La eutonía: un camino hacia la experiencia total del cuerpo. Madrid: Paidós Ibérica Ediciones.

Lagardera, F. (2009). El área de conocimiento de la acción motriz. Acción Motriz, 3, 5-15. Recuperado de http://mdc.ulpgc.es/cdm/ref/collection/amotriz/id/11

Mallarino, C. (2010). La articulación de la dimensión motora y la dimensión cognitiva: una propuesta renovada para la educación del movimiento. Cali: Editorial Bonaventuriana.

Morin, E. (1999). Los siete saberes para la educación del futuro. París: Unesco.

Ospina, W. (13 de noviembre de 2011). Educación. El Espectador.

Proyecto Educativo del Programa - PEP. (2012). Facultad de Cultura Física, Deporte y Recreación. Universidad Santo Tomás. Bogotá: Ediciones USTA. 